\title{
Low-dose ionizing radiation as a hormetin: experimental observations and therapeutic perspective for age-related disorders
}

\author{
Alexander Vaiserman (D) Jerry M. Cuttler · Yehoshua Socol
}

Received: 11 October 2020/Accepted: 24 November 2020/Published online: 9 January 2021

(C) The Author(s), under exclusive licence to Springer Nature B.V. part of Springer Nature 2021

\begin{abstract}
Hormesis is any kind of biphasic doseresponse when low doses of some agents are beneficial while higher doses are detrimental. Radiation hormesis is the most thoroughly investigated among all hormesis-like phenomena, in particular in biogerontology. In this review, we aimed to summarize research evidence supporting hormesis through exposure to low-dose ionizing radiation (LDIR). Radiationinduced longevity hormesis has been repeatedly reported in invertebrate models such as C. elegans, Drosophila and flour beetles and in vertebrate models including guinea pigs, mice and rabbits. On the contrary, suppressing natural background radiation was repeatedly found to cause detrimental effects in protozoa, bacteria and flies. We also discussed here the possibility of clinical use of LDIR, predominantly for age-related disorders, e.g., Alzheimer's disease, for which no remedies are available. There is accumulating evidence that LDIR, such as those commonly used in X-ray imaging including computer tomography, might act as a hormetin. Of course, caution should be
\end{abstract}

A. Vaiserman $(\bowtie)$

Institute of Gerontology, Vyshgorodskayast. 67, 04114 Kyiv, Ukraine

e-mail: vaiserman@geront.kiev.ua

J. M. Cuttler

Cuttler \& Associates, Vaughan, ON, Canada

Y. Socol

Jerusalem College of Technology, Jerusalem, Israel exercised when introducing new medical practices, and LDIR therapy is no exception. However, due to the low average residual life expectancy in old patients, the short-term benefits of such interventions (e.g., potential therapeutic effect against dementia) may outweigh their hypothetical delayed risks (e.g., cancer). We argue here that assessment and clinical trials of LDIR treatments should be given priority bearing in mind the enormous economic, social and ethical implications of potentially-treatable, age-related disorders.

Keywords Low-dose ionizingradiation - Radiation hormesis · Hormetin · Longevity · Animal models . Age-relateddisorders

\section{Introduction: what is radiation hormesis?}

Back in the 1880s, Hugo Schulz observed that low doses of many toxic agents, like mercury and formaldehyde, enhanced the vitality of yeast cells (Schulz 1887, 1888). The term "hormesis" was first introduced in 1940s in the context of chemical toxins (Southam and Erhlich 1943). Hormesis in general is any kind of biphasic dose-response when low doses of some agents are beneficial while higher doses are detrimental (Calabrese 2015, 2018, 2019). According to the present knowledge, hormesis-inducing agents 
('hormetins') include but are not limited to a variety of physical and chemical factors such as heat and oxidative stress, various food components, micronutrients, intermittent fasting, calorie restriction, physical exercise etc. (Musci et al. 2019; Rattan and Kyriazis 2019; Calabrese et al. 2020a).

Radiation hormesis is the most thoroughly investigated among all hormesis-like phenomena, in particular in biogerontology. Speaking about radiation hormesis, we should point two somewhat different uses of the term 'hormesis'. Since radiation carcinogenesis is usually considered to be the single most important detrimental health factor of ionizing radiation, radiation hormesis is sometimes understood in the narrow sense that low radiation doses can suppress cancer. In this narrow sense, curing arthritis or pneumonia is not viewed as a hormetic effect. Accordingly, there are two quite different meanings of the term 'low dose'. In the context of radiation protection and many fields of radiobiology, 'low dose' is understood to be $100 \mathrm{mGy}$ or less-there being a consensus (more or less) that there is no solid evidence for radiation carcinogenesis below $100 \mathrm{mGy}$. However, in the field of radiation oncology where the daily dose fraction is typically $2000 \mathrm{mGy}$ and 6 weeks of therapy amounts to a total dose of $60,000 \mathrm{mGy}$, a single $1000 \mathrm{mGy}$ dose to treat pneumonia is regarded as a low dose (Calabrese et al. 2020b). In this review article, we use the term 'hormesis' in the wide sense of biphasic dose-response, and consequently 'low dose' as corresponding to the beneficial-effect part of the dose-response curve (Cuttler 2020). Therefore, the meaning of 'low dose' is species-specific.

In this review, we aimed to summarize research evidence supporting hormesis through low-dose ionizing radiation (LDIR) in age-related disorders and discuss the possibility of using this phenomenon in clinical settings.

\section{Historical overview}

Since the discovery of a radioactivity in 1896 , there is vast amount of data regarding health effects from ionizing radiation exposure. Sufficiently high doses undoubtedly cause harm - that is a matter of proper scientific consensus. However, a major controversy exists among scientists and medical professionals regarding health effects of radiation at relatively low doses and dose rates that does not cause immediate harm. At the end of the XIX and early XX century, there was a general belief that beneficial consequences of irradiation are widespread and nearly miraculous. "Mild radium therapy" has been widely used and probably more widely misused. It was claimed, e.g., that blindness could be cured by using X-rays. It has been advertised that several mixtures might treat about 150 disorders, including lassitude and sexual impotence. Over the period between 1925 and 1930, about 400,000 bottles with radium-containing water have been sold. The tragic death of the famous millionaire Eben M. Byers in 1932 as a consequence of radium poisoning became a widely-known event that alerted both the public and the medical community of adverse radiation effects. This event probably ended the era of the "mild radium therapy" (Blaufox 2019).

After the Hiroshima and Nagasaki atomic bombing in 1945, the attitude to ionizing radiation began to lean to another extreme: ionizing radiation became connected in public mind with nuclear apocalypse. The linear no-threshold (LNT) model for radiation risk assessment, introduced after Muller's discovery of radiation-induced mutations in 1927 , became popular. This model suggests that any radiation exposure constitutes the risk that increases proportionally with increasing exposure. The main radiation concern was mutagenesis. Later (at end of the 1950s), after no radiation mutagenesis was found in the A-bomb survivors' descents (Satoh et al. 1996; Kodaira et al. 2004), carcinogenesis became the main concern. LNT has been introduced as a reasonable operational model for the radiation protection only. Formally speaking, this is valid even now: UNSCEAR, ICRP and other scientific bodies officially advise against using LNT for cancer morbidity/mortality predictions. De facto, however, LNT acquired the status of scientific theory, though supporting evidence is at least inconclusive. Extrapolation of effects from the high to low exposure doses is not founded as any other extrapolation. Moreover, such extrapolation neglects the fact that all organisms were always exposed to ionizing radiation and that multiple mechanisms to repair radiation damage evolved during the evolution (Boothby et al. 2019). The model of radiation hormesis is based on the assumption that repair mechanisms, triggered by the LDIR, might be efficacious not only against the radiation-induced damage, but also against damage from other stressors. Therefore, these mechanisms 
may cause overall improvement of health including decreased cancer (Calabrese et al. 2015; Costantini and Borremans 2019).

Beneficial effects of LDIR are known since the ancient times: already Herodotus and Hippocrates describe beneficial effects of radon springs. In the modern times, Roentgen-ray stimulation of growth has been observed in X-ray exposed algae (Atkinson 1898) and these findings were confirmed in subsequent studies (Conter et al. 1983). As mentioned above, X-rays and radium sourceshave been widely applied in the first half of the XX century for treating arthritis, pneumonia and more (Calabrese et al. 2020b). During the Manhattan Project, rodents exposed to inhaled uranium dust were studied. The scientists were surprised to learn that exposed animals were healthier and were characterized by higher life expectancy and more offspring than the controls, though the dust concentration had been expected to be fatal at the experimental set-up (Brucer 1990). Later in 1958, the first United Nations Scientific Committee on the Effects of Atomic Radiation (UNSCEAR) report provided experimental evidence for the longer survival of rodents such as mice and guinea pigs after exposure to low doses of gamma radiation and fast neutrons. These data have been interpreted as indicative of existence of a threshold, but the hormesis was not mentioned (UNSCEAR 1958; Calabrese 2020).

The pioneering studies of hormetic phenomenon carried out in the mid-20th century pointed that hormetic effects can be more pronounced in populations maintained in suboptimal conditions or in nonhealthy individuals (Sacher 1977). For example, statistically significant life extension was observed in short-lived dogs, but not in the dog population in general (Cuttler et al. 2017a, b). However, when experiments with chronic radiation exposure have been done with high standards of the animal care, hormetic effects diminished but were still observable (Sacher 1977). Unfortunately, since 1960s hormesislike effects of LDIR have been systematically ignored by both the medical community and by radiation protection agencies-despite more than 2000 peerreview papers on this subject in the PubMed database as for August 2020. Over the previous decades, beneficial effects induced by the LDIR exposure were repeatedly found in cell cultures, microorganisms, plants, and different invertebrate and mammal models. The effects were observed at all levels including the biochemical, cellular, tissue and the whole-organism ones. Radiation hormesis was revealed for various physiologic functions. Observed effects included enzyme induction, growth, cell division, neuromuscular development, metabolism, hearing, visual acuity, as well as memory and learning performance. In mammals, radiation hormesis has been demonstrated to enhance protection against various infectious and neoplastic disorders, to improve fertility and to increase longevity (Scott 2014). From the 1950s until the beginning of 1980 s, four major mechanisms were generally discussed to explain this phenomenon. It was suggested that radiation exposure can: (1) reduce the amount of detrimental bacteria in the organism (Sacher 1956); (2) inactivate gonadal function causing the reallocation of vital resources in favor of somatic maintenance at the expense of reproduction (Lamb 1964); (3) reduce the oxygen consumption rate and, therefore, metabolic activity (Allen and Sohal 1982); (4) induce over-compensatory repair responses (Cork 1957; Carlson and Jackson 1959). Presently, only the last assumption-over-compensatory repair-is generally accepted. In line with current assumptions, the contributing mechanisms include, along with stimulation of the DNA repair, modification of gene expression, stress protein production, detoxication of reactive oxygen species (ROS), release of growth factors, activation of membrane receptors, compensatory cell proliferation and stimulation of the immune system (Feinendegen 2005; Calabrese et al. 2010; Shibamoto and Nakamura 2018; Vaiserman et al. 2018).

Life extension is among the well-established beneficial health effects of LDIR (Cameron 2003). The effects of radiation on longevity have been evaluated in a variety of animal models. Lifespan decrease is well-known outcome of the high-dose radiation exposure (Lamb 1964; Brown 1966; Gould and Clark 1977; Giess and Planel 1977; Giess 1980). However, lifespan extension has been also repeatedly observed in laboratory animals irradiated with low doses. In these studies, the mean lifespan was often increased by $10-30 \%$ while the maximal lifespan has been usually unchanged (Calabrese and Baldwin 2000; Cuttler et al. 2017a, b). 


\section{Radiation hormesis in invertebrate models}

Controversial data about effects of LDIR exposure on lifespan have been obtained with a nematode Caenorhabditis elegans. Multiple stressors-like heat, ROS-generating chemical juglone, hyperbaric oxygen, etc., - promoted enhanced lifespan in the worms, but treatment with ultraviolet radiation or with X-rays did not (Cypser and Johnson 2002). No lifespan extension has been also obtained following gamma-irradiation at the dauer larvae stage (Yeargers 1981). Substantial occasional (non-repeatable) increase of survival in $C$. elegansafter radiation exposure with intermediate doses of 100-300 Gy was reported only once, in the study by Johnson and Hartman (1988).

Radiation hormesis was repeatedly reported in insect models (Calabrese 2014). Experiments with a flour beetle such as Triboliumconfusum, are among the first studies providing evidence for this phenomenon (Davey 1917, 1919). In the experiment with acute exposure, five X-ray doses were applied (Davey 1917). These doses were later reported (cited in Calabrese and Baldwin 2000) as $100-500 \mathrm{~mA} / \mathrm{min}$ at $25 \mathrm{~cm}$ at $50 \mathrm{kV}(100-500 \mathrm{MAM} / 25$ at $50 \mathrm{kV})$, or 5-25 Gy; the dose of $12.5 \mathrm{MAM} / 25$ corresponds to approximately $60 \mathrm{rad}$ or $0.6 \mathrm{~Gy}$ (Cork 1957). In this experiment conducted with 1100 beetles, the least dose required to kill all test animals (LD100) was 500 $\mathrm{MAM} / 25$ at $50 \mathrm{kV}(5 \mathrm{~Gy})$. Death rates lower than those found in controls were, however, observed by irradiation with 100 or $200 \mathrm{MAM} / 25$ at $50 \mathrm{kV}$ (5-10 Gy). In the subsequent research, the effects of $\mathrm{X}$-rays on longevity have been evaluated following either acute X-ray exposure (as in previous study) or through daily exposures (Davey 1919). In the daily exposure experimental block performed with appr. 950 beetles per each group, five doses have been applied, ranging from 6.25 to $50 \mathrm{MAM} / 25$ at $50 \mathrm{kV}$ ( 0.3 to $2.5 \mathrm{~Gy}$ ) per day. By 30 days after irradiations, $25-40 \%$ decrease in mortality was demonstrated in experimental groups irradiated with three lowest doses. In the second experimental block conducted with $\sim 850$ beetles per group, single doses in the range of 100-400 MAM/25 at $50 \mathrm{kV}$ (5-20 Gy) were used. Confirming the results from the initial study, a reduced mortality rate has been found by 20 days after the irradiation. The Davey's findings were subsequently confirmed in experiments by Cork (1957) conducted with large number of flour beetles. In these studies, however, irradiations were performed with cesium-137 used as a source of gamma rays. Both acute and chronic radiation exposures were shown to be able to promote lifespan extension. More recently, radiation-induced longevity hormesis has been obtained in another beetle species such as Triboliumcastaneum (Ducoff 1975). Irradiation reduced the early mortality rate thereby resulting in more "rectangular" survival curves. However, little or no increase in maximal lifespan was revealed. Moreover, irradiated insects were found to be more resistant to ether hyperbaric oxygen or heat stresses (Lee and Ducoff 1983; Ducoff and Lee 1984). Interestingly, stress resistance was found to be higher in the irradiated adults than in young controls, thus, this effect was not simply due to slowing of the aging rate.

Low-dose gamma irradiation also was found to be able to increase mean lifespan of the house fly, Musca domestica (Allen and Sohal 1982). Adult house flies exposed to 0, 20, 40 and $66 \mathrm{kR}$ (kR-kiloroentgen, about $10 \mathrm{~Gy} ; 1 \mathrm{R} \approx 10 \mathrm{mGy}$ ) were maintained in conditions of either low or high physical activity. In the high-activity cohort, mean lifespan of those flies who have been exposed to 20 or $40 \mathrm{kR}$ was larger than that in the control insects, but it has been significantly decreased after irradiation with $66 \mathrm{kR}$. In both sexes, the radiation exposure led to a significant reduction in oxygen consumption rate. The effects of radiation were shown to be substantially dependent on environmental conditions. Life-extending effects were detected only if flies were reared in groups, i.e., a condition which promotes a high locomotor activity level. If singly reared (a low-level locomotor activity condition), the longevity hormesis did not appear. In addition, irradiated insects had enhanced longevity compared to control individuals only when the latter have been kept in suboptimal conditions. Irradiation also resulted in decreased rate of accumulating fluorescent age pigment (lipofuscin) in high-activity groups, while increased rate of lipofuscin accumulation was found in flies maintained in low-activity conditions (Allen 1985). The reduced metabolic activity was proposed as a potential explanation for such a radiation-induced life-lengthening (Allen and Sohal 1982).

The longevity-modulating effects of ionizing radiation were most thoroughly investigated in the Drosophila melanogaster. High doses have been 
repeatedly shown to lead to life shortening of fruit flies (Lamb 1964; Nelson 1973; Giess and Planel 1977; Gould and Clark 1977; Giess 1980). In discussing the reported life-extending effects of irradiation in fruit flies, Sacher (1963) has noted a reduced variability in average survival times among replicates. In this discussion, he attributed both the observed reduction in variability and the improved survival to neutralization of some disadvantageous environmental factor(s) via the radiation exposure. By the Sacher's point of view, it cannot be, however, determined whether such a reduced efficiency is caused by inactivation of certain adverse environmental factor(s) or from increasing the resistance induced by a radiation exposure. Alternative hypothesis for explaining the observed hormetic effects (at least in female flies) was proposed by Marion Lamb (1964). She has suggested that irradiation may lead to a sterility in female flies and that the extension of longevity might be due to lowering the level of synthetic metabolism in gonads. In supporting this hypothesis, she has demonstrated that mutant female flies without ovaries did not exhibit a longer lifespan following the irradiation. Later, Giess et al. (1980) have, however, postulated that radio-induced sterility is not a cause of these effects. In this study, no lifespan-modulating effects were obtained following exposure to $10 \mathrm{kR}$, a dose known to completely inhibit fecundity. These results cause doubt that reduced fecundity per se could be a plausible mechanism for the hormetic effects of irradiation. In addition, such effects were found to be more pronounced if a dosefractionation regime was used. Females demonstrated a higher increase in longevity following dose fractionation compared to the age-matched males (Mohsin 1979). More specifically, females demonstrated $31 \%$ increase in lifespan, whereas only $12 \%$ increase was observed in males.

In a series of studies, the potential role of the apoptosis (programmed cell death) in the radiationinduced longevity hormesis in Drosophila has been investigated. Chronic irradiation with cumulative doses of 0.6 to 0.8 Gy resulted in an increase in mean lifespan in male wild-type D. melanogaster and in decreased lifespan in mutant Drosophila strains defective in DNA repair and displaying an enhancing sensitivity to an apoptosis induction (Zainullin and Moskalev 2001). In the mutant strain carrying the proapoptotic 'reaper' (rpr) gene, an increased lifespan was obtained either after the irradiation and/or following treatment with the inductor of apoptosis, etoposide (Moskalev and Zainullin 2001). Moreover, an association has been shown between the radioinduced apoptosis in cells of the larval ganglion and the aging rate (Moskalev and Zainullin 2004). The authors assumed that these effects were due to eliminating damaged or unwanted cells by the radiation-induced apoptosis (Moskalev et al. 2006). An important role of genes encoding heat shock proteins and heat shock factors (Moskalev et al. 2009) as well as longevity-associated factors such as FOXO, SIRT1, JNK, ATM, ATR, and p53 (Moskalev et al. 2011) in inducing radiation-induced hormetic effects in fruit flies also has been demonstrated. More recently, significant contribution of genes implicated in the nucleotide excision repair (mei-9, mus210, Mus209), base excision repair (Rrp1), DNA double-stranded break repair by homologous recombination (Brca2, spn-B, okr), DNA damage sensing (D-Gadd45, Hus1, mnk), non-homologous end joining (Ku80, WRNexo), as well as Mus309 known to participate in the DNA repair processes has been revealed (Koval et al. 2020). In flies with mutations in these genes radiation hormesis was completely absent or appeared to a lesser extent than in wild-type Canton-S strain. The LDIR exposure also led to hormesis-associated alterations in gene expression in Drosophila; these changes, however, were found to be not dose-dependent (Zhikrevetskaya et al. 2015). In a genome-wide analysis, approximately $13 \%$ of the genome of lowdose irradiated male D. melanogaster displayed changes in gene expression; among them, many of aging-related genes have been shown to be significantly regulated (Seong et al. 2011).

The effects of X-ray irradiation early in life on the flies' lifespan were also revealed. It must be taken into account that fruit flies develop with metamorphosis, and ontogenetic stages differ significantly in radiosensitivity (see Fig. 1 for illustration). It is because Drosophila imago consists mainly of radioresistant postmitotic tissues, with the exception of some gut cells and the gonads (Rogina 2011), while active cell division occurs during pre-adult stages from egg to pupa.

A significant trend to decrease median lifespan with increasing irradiation dose has been observed in both male and female flies irradiated with 1.2, 2.1, 4.2, 7.5 and 17.1 Gy at larval stage. The maximum lifespan, 


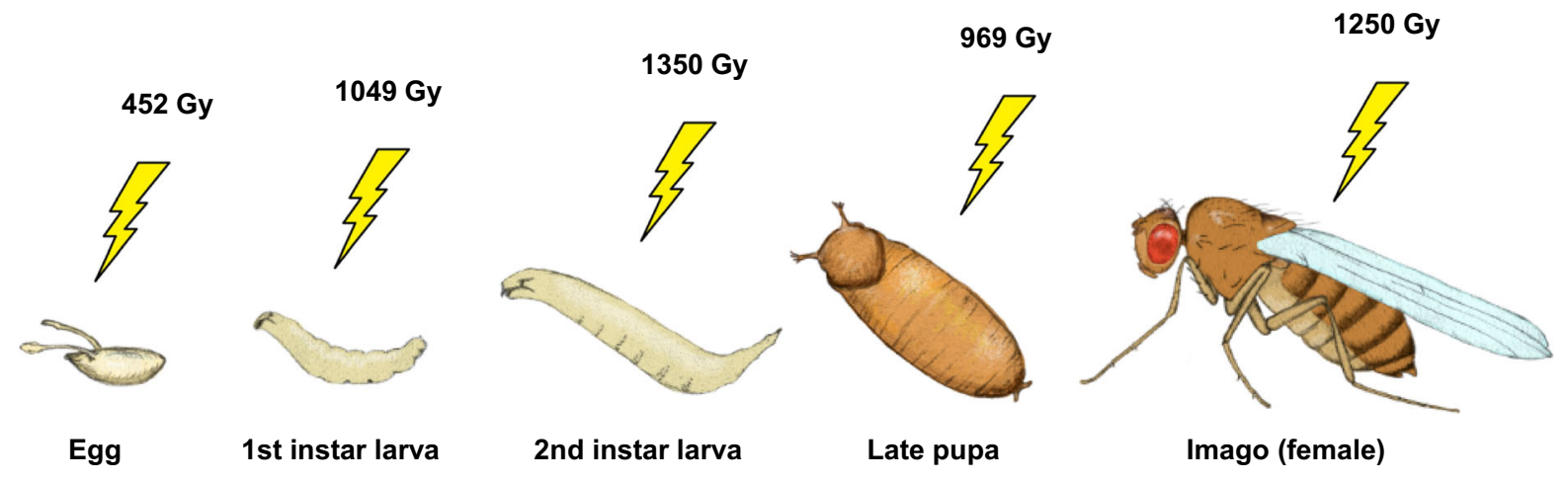

Fig. 1 The median lethal dose $\left(\mathrm{LD}_{50}\right)$ in different life stages of Drosophila melanogaster. The figure is based on the data from Paithankar et al. (2017)

however, was found to be increased on $11.5 \%$ and $12.7 \%$ in males irradiated with 1.2 and $2.1 \mathrm{~Gy}$, respectively (Vaiserman et al. 2004a). X-irradiation of the 1-h eggs with doses of $0.25,0.50,0.75,1,2$ and 4 Gy was also found to affect lifespan (Vaiserman et al. 2003a). Longevity hormesis has been found in males (but not in females) irradiated with 0.5 and 0.75 Gy. X-ray irradiation at the egg stage with 0.75 Gy caused ultrastructural changes in the flies' brain cells (Vaiserman et al. 2003b). Irradiations at this stage also caused DNA modifications such as decreased amounts of DNA segments resulting from a cleavage of the $\mathrm{S} 1$ nuclease-sensitive sites $(<3 \mathrm{~kb})$ compared to that in control flies (Fig. 2). The higher stability of DNA might be the result of activating the

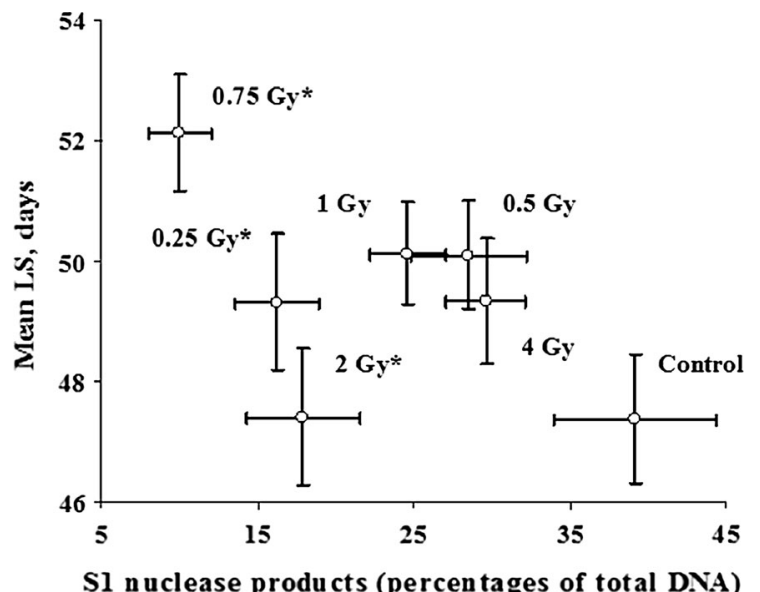

Fig. 2 Percentages of the S1 nuclease products plotted vs. the male's mean life span. Standard errors are shown for estimates of both variables. Reproduced from Vaiserman et al. (2004a) with permission of Springer Nature repair system of irradiated flies. It has been hypothesized by the authors that these effects were due to structural and/or functional DNA modifications which occurred following the irradiation at the egg stage and persisted in adult tissues. Such modifications, if any, might change the repair and/or transcription processes, thereby affecting the lifespan. Evidence was also obtained that effects induced by early-life X-ray irradiation may persist across generations. Irradiation of 1-h eggs with $0.25,0.5$ and 0.75 Gy resulted in decreased body weight and increased locomotor (both photo- and geotactic) activities in F0 and F1 generations (Vaiserman et al. 2004b). Moreover, increased resistance to the starvation and heat shock stresses as well as longevity hormesis have been observed in irradiated flies and their offspring. Confirming evidence for the possibility of cross-generational transmission of effects induced by gamma irradiation in ancestral generation on the flies' longevity has been also observed in the Shameer et al. (2015) study. Irradiation of two-to three-day-old male parental flies with small-to-moderate doses (1-10 Gy) lead to a significant lifespan extension in both male and female offspring, whereas exposure to higher doses (40 and $50 \mathrm{~Gy}$ ) resulted in a decreased longevity in F1 and F2 offspring generations. These effects on longevity disappeared in the F3 generation.

\section{Radiation hormesis in vertebrate models}

Radiation-induced longevity hormesis was reported in several vertebrate models. First evidence for that has 
been provided by Lorenz and colleagues from the U.S. National Cancer Institute. In an initial study, guinea pigs, rabbits and LAF1 mice have been exposed to 8.8, $4.4,2.2,1.1$ and $0.11 \mathrm{R}$ per day from early adult age until death (Lorenz et al. 1954). Irradiated animals have been reported to live longer by $2-14 \%$ than controls. However, these beneficial outcomes were unexpectedly accompanied by increased tumor incidence in several experimental groups. These findings were subsequently confirmed in the study by Lorenz et al. (1955). The authors hypothesized that these effects could be caused by improvement of immune defense mechanisms against infectious agents which are known to be the most common cause of death in rodents. A significant increase of median and maximal survival times above control values has been observed in rats exposed for 12 months to gamma irradiation at daily irradiation doses ranging from 0.3 to $4.0 \mathrm{R} /$ day combined with heat or cold stresses (Carlson et al. 1957; Carlson and Jackson 1959). Most substantial life extension (increase of 30\%) has been observed after exposure to $2.5 \mathrm{R} /$ day. More recently, significant lifespan extension was found in female C57BL/6 mice chronically exposed to gamma irradiation at very lowdose rates ( 7 or $14 \mathrm{cGy} / \mathrm{year}$ ): the median survival times were 549 days in control animals, while they reached 673 days in both exposed groups (Caratero et al. 1998). These findings, however, were not confirmed in a subsequent study by the same authors where no significant differences, neither in longevity nor in cancer or non-cancer disorders, were observed among control and irradiated animals (Courtade et al. 2002). Chronic low-dose rate gamma irradiation at 0.35 or $1.2 \mathrm{mGy} /$ hour promoted longevity in MRLlpr/lpr mutant mouse strain with a deletion in the apoptosis-regulating Fas gene known to markedly shorten lifespan owing to severe autoimmune disorder (Ina and Sakai 2004). Further extension of irradiation period to the entire lifespan at the same dose rates led to an even more pronounced increase of survival time (Ina and Sakai 2005). The 50\% survival time for the control non-treated mice, 134 days, was found to be prolonged nearly four-fold (to 502 days) following the life-long irradiation at $1.2 \mathrm{mGy} /$ hour. In addition, such a radiation exposure led to the immune system activation. More specifically, it resulted in a substantial increase in the numbers of CD4 + CD8 + T cells in the thymus and CD8 $+\mathrm{T}$ cells in the spleen, and also in a significant decrease in the numbers of
$\mathrm{CD} 3+\mathrm{CD} 45 \mathrm{R} / \mathrm{B} 220+$ cells and CD45R/B220 + $\mathrm{CD} 40+$ cells in the spleen. No evidence for prolonged longevity in mice exposed to very low-doserate gamma-rays was, however, found in research by Tanaka et al. (2003) conducted with an extremely large mouse sample (total $n=4000$ ). Irradiations were carried out during 400 days with $137 \mathrm{Cs}$ as a source of gamma-rays at dose rates of $0.05,1.1$ and $21 \mathrm{mGy} /-$ day. The accumulated doses were about 20, 400 and $8000 \mathrm{mGy}$, respectively. The lifespan of females irradiated with $1.1 \mathrm{mGy} /$ day and animals of both sexes irradiated with $21 \mathrm{mGy} /$ day was significantly decreased compared to those in the control group. Recently, life-shortening effects of chronic low-doserate irradiation (400 days at $20 \mathrm{mGy} /$ day) were reported in calorie-restricted mice (Yamauchi et al. 2019). However, hormesis-like effects were reported by another study in ApoE-/- mice following very lowdose and dose-rate external chronic radiation exposure of up to $28 \mu \mathrm{Gy} / \mathrm{h}$ for 8 months (Ebrahimian et al. 2018). These effects were found to be associated with an increased expression of anti-inflammatory and antioxidative gene. Remarkably, dose rates used in this study (12 and $28 \mu \mathrm{Gy} / \mathrm{h}$ ) were similar to those measured in contaminated areas like Chernobyl and Fukushima.

Evidence for radiation-induced longevity hormesis has been also obtained in several non-rodent mammalian species. One example is the study conducted with chipmunks, Tamias striatus (Thompson et al. 1990). Wild chipmunks have been captured, exposed to ionizing radiation at single doses of either 200 or 400 rads, and returned to their natural habitats. Irradiated chipmunks demonstrated a biphasic response in age-specific mortality rate. A residuum of unrepaired injury appeared to persist and manifest throughout the entire lifespan. However, another response-longevity hormesis-was also evident in this study. Effects of LDIR were also investigated in dogs. Cuttler et al. (2018a, 2018b) recently determined a dose rate threshold at about $600 \mathrm{mGy}$ per year for lifespan reduction in dogs irradiated lifelong with cobalt-60 gamma radiation. In dog models, hormetic effects following irradiation were also demonstrated. In a meta-analysis of two large-scale studies, one with ten groups exposed to different gamma dose rates and other with eight groups exposed to different lung burdens of plutonium, Cuttler et al. (2017a, b) showed that dogs (especially short-lived ones) benefit when 
radiation is moderately above the background level. The maximal lifespan increase occurred at $50 \mathrm{mGy} /$ year. For inhaled $\alpha$-emitting particulates, longevity of short-lived dogs was shown to be substantially increased below the threshold for harm. In beagles, for lifetime cumulative skeletal doses below $10 \mathrm{~Sv}$ from ingested Sr-90, the risk of bone sarcoma was significantly lower than that for controls (Raabe 2010, 2015).

\section{Detrimental outcomes of suppressing background radiation}

One strong argument in favor of beneficial effects of LDIR was provided from the facts indicating that suppressing background radiation can detrimentally affect the viability of many organisms. This could be because life on our planet has evolved in conditions of continuous exposure to ionizing radiation, which 3.5 billion years ago was roughly three times higher than presently (Jaworowski 1997). Exposure to artificially lowered levels of natural radiation was found to cause deficiency symptoms in various protozoa and bacteria. These symptoms included, among others, the dramatically decreased proliferation of these organisms (Planel et al. 1966, 1969). Lead shielding of cultures of blue-green algae, Synechococcus lividus, also led to lowering the cell growth rate (Conter et al. 1983). This effect disappeared when a normal radiation level (equal to that of background radiation) has been restored within the lead chambers. Irradiation with Th-source at 14-fold natural background dose rate, on the contrary, stimulated the growth of this alga. A study performed with a protozoa Paramecium tetraurelia and cyanobacteria Synechococcus lividus, which have been either shielded against the background radiation or exposed to low-dose gamma radiation, also showed that radiation may stimulate the proliferation rate of both these single-cell organisms (Planel et al. 1987). The magnitude of this hormetic effect depended either on internal factors (age of starting cells) or external factors (lighting conditions). A stimulatory effect occurred only in a restricted dose range and disappeared with the increase of the dose rate above50 $\mathrm{mGy} / \mathrm{year}$. Similar research findings were obtained with $D$. melanogaster fruit flies. Shielding from natural ionizing radiation resulted in a delayed development (Planel et al. 1967a), and also in a decreased reproductive performance (Planel et al. 1967b) and longevity (Giess and Planel 1973; Planel and Giess 1973).

Overall, these findings indicate that background ionizing radiation may play essential roles in determining the adaptive potential of an organism. Based on this, Sacher (1977) has assumed that free radicals generated following exposure to background radiation may act as primers for certain metabolic processes, thereby affecting the viability of all living organisms. This assumption was subsequently confirmed in a variety of studies. Currently, it is commonly recognized that free radicals such as reactive oxygen species (ROS) or reactive nitrogen species (RNS) are important second messengers in various signal transduction pathways critical for cell growth and proliferation; so, they may play essential roles in multiple vital processes (Milkovic et al. 2019; Huang and Li 2020).

\section{Mechanistic considerations}

The LNT model implies that the organism has constant capability to repair damages caused by radiation exposure, irrespective of dose and dose rate. However, there is increasing evidence that such a suggestion is not true. It has been consistently reported that many organism's responses may be inhibited by high-dose radiation exposures but stimulated by LDIR exposures. In particular, such pattern of response has been well documented for the immune response (Cui et al. 2017) and DNA repair (Pollycove and Feinendegen 2003). Accumulating data indicate that response to irradiation depends on factors such as radiation source distribution, radiation track structure, temporal pattern of radiation exposure, total accumulated dose, dose rate, as well as on the structure and dimension of the biological targets (Howell 2016). The radiation hormesis model, in contrast to the LNT model, predicts that LDIR could induce multiple adaptive responses, and such responses might prevent certain environmentally-induced unfavorable health effects. With regard to DNA repair capacity, the resulting effect can be dependent on the balance between the DNA damage rate (linear with the dose) and particular mechanisms which are responsible for cellular defense (Dobrzyński et al. 2019). Therefore, the response to LDIR exposure could evolve from damage on the molecular level, to beneficial adaptive response on a 
whole-body level. When the dose does not exceed $0.1 \mathrm{~Gy}$, the beneficial outcomes tend to outweigh the harmful ones (Feinendegen et al. 2007; Scott and Tharmalingam 2019). The LDIR can likely stimulate repair mechanisms able to repair the primary damage and protect the organism from subsequent stressfuleither radiation or other-exposures (Kim et al. 2015). In addition, following these processes, preneoplastic and other damaged cells could be eliminated by apoptosis, immune surveillance and cellular competition (Anzai et al. 2012). The key components of this radiation-induced hormetic response include: ROS scavenging, synthesis of heat shock proteins, secreting specific growth factors and cytokines, activating the cell-membrane receptors, as well as compensatory cell proliferation (Feinendegen et al. 2007; Szumiel 2012). These processes are likely mediated by coordinated adaptive alterations in specific epigenetic pathways (Vaiserman 2008, 2010). Adaptive responses induced following acute exposure to LDIR have differing time schedules depending on the implicated protective pathways. These responses, e.g., DNA repair, may be activated immediately or with delay of hours to days, and some of them (e.g., immune response) may last for several days to weeks or even months. If these protective mechanisms act more efficiently in a lowdose range, then it is quite reasonable that doseresponse patterns observed following exposures to LDIR could be not linear but rather threshold or biphasic (Agathokleous and Calabrese 2020). The observed relationships may be apparently affected by various integrative endpoints including patterns of growth, tissue repair, cell proliferation, adaptive preconditioning responses, complex behaviors and also aging processes (Calabrese 2018). Furthermore, these associations could be further complicated by adaptive responses in cells pre-exposed to LDIR, genomic instability manifested in the progeny of irradiated cells as well as by effects in non-targeted cells (so-called bystander effects) (Mothersill et al. 2019).

Following an irradiation, the strategies of cell defense depend on the radiation dose and dose rate, and also on the amount of damages in neighboring cells (Pouget et al. 2018). However, it remains unclear so far whether these mechanisms may act cooperatively at the whole-organism level. Over some last decades, accumulating evidence was provided that low-dose/low-dose-rate radiation exposures may trigger protective responses in vivo as well (see Fig. 3 for schematic illustration). Such exposures were repeatedly shown to activate multiple inter- and intracellular pathways, thereby causing improved protection against many cancers and other genomic instability-related disorders (Feinendegen et al. 2007). Below, molecular, cellular and whole organism-level mechanisms potentially underlying hormetic effects of LDIR are discussed in more details.

\section{DNA repair}

DNA Double-Strand Breaks (DSBs) induced by various environmental factors including ionizing radiation are well known to be able to disturb genome integrity and impair cellular viability. Increasing evidence, however, indicates that danger from exposures to LDIR is generally negligible as compared to DNA damage caused by oxidation process normally occurring during the metabolism (Pollycove and Feinendegen 2003; Feinendegen 2005). Moreover, LDIR-induced protective responses may likely overcompensate genotoxic effects caused by byproducts of the normal oxidative metabolism (Azzam et al. 2016). This point of view is based on research data indicating that non-radiation damage of DNA is substantially larger in different tissues than DNA damage caused by radiation exposure at background (and even at much higher) levels (Pollycove and Feinendegen 2003).

Based on these theoretical considerations, it is suggested that LDIR may have a dual effect on DNA. Absorption of radiation energy by the DNA molecule represents a direct outcome of the radiation exposure. This absorption can induce various structural changes in the DNA. Moreover, free radicals produced through interactions of radiation with certain molecules of intracellular water may result in a damaged DNA structure. The probability for a DNA damage per each energy deposition event increases proportionally to the absorbed dose. At the background-level radiation exposure, the DNA damage rate is orders of magnitude lower than that induced by different endogenous sources-primarily, by ROS occurring as byproducts of the normal metabolism (Pollycove and Feinendegen 2003). DSBs caused by acute radiation exposure of up to $200 \mathrm{mGy}$ have been repeatedly shown to be efficiently repaired at $24 \mathrm{~h}$ post-irradiation in actively proliferating human cells (Rothkamm and Lobrich 

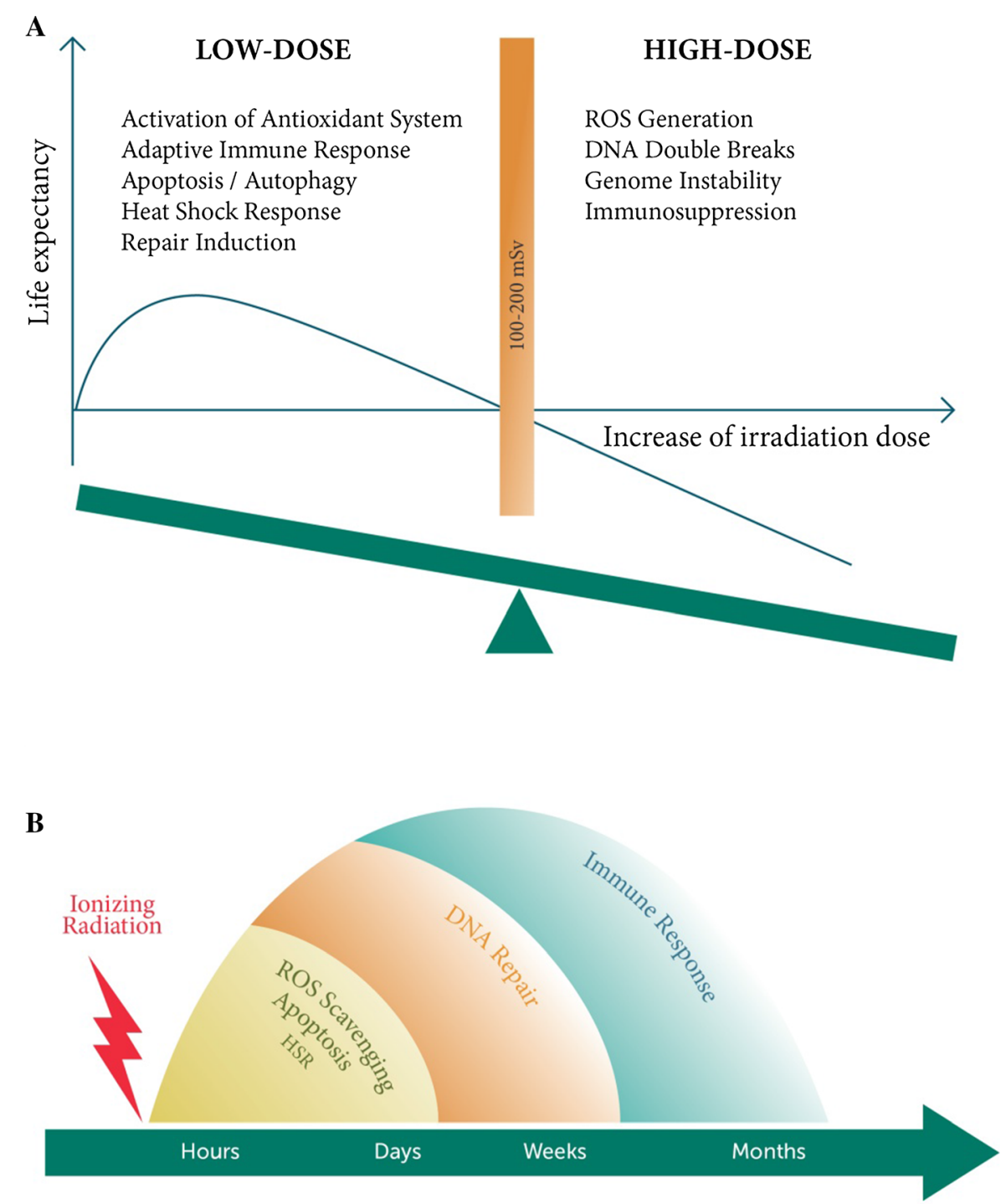

Fig. 3 a Schematic representation of molecular and cellular mechanisms operating at low- and high-dose radiation exposures; b Time schedule of pathways involved in radiationinduced adaptive response. HSR: Heat shock response. The

2003). Furthermore, accumulating evidence demonstrate that level of DSBs in cell cultures exposed to a LDIR usually decreases to level characteristic to that in unexposed cultures if irradiated cells are allowed to proliferate after the radiation exposure. This can likely be due to elimination of cells carrying unrepaired DSBs (Rothkamm and Lobrich 2003). These findings demonstrate that effects of LDIR are in strong contrast with those of high-dose exposures. Damages caused by the LDIR can be completely recovered while highdose exposures usually lead to the occurrence of figure is reproduced from the article of Vaiserman et al. (2018) distributed under the terms of the Creative Commons Attribution-Noncommercial 4.0 License. Copyright (C) The Author(s) 2018

residual DSBs. Thus, whereas linear dose-response relationship may indeed exist for the initial DSB induction, the DNA damage induced by low dose radiation has few chances to persist for any significant time period in cell populations (Suzuki and Yamashita 2012). In addition, adaptive responses against DNA damage may occur following the LDIR exposure (Nenoi et al. 2015). Remarkably, such protective effects have been demonstrated to generally disappear at doses which exceed 100-200 mGy, and they were never observed following acute exposures which 
exceed 500 mGy (Feinendegen 2005). Therefore, it can be assumed that LDIR could stimulate DNA repair pathways thereby reducing levels of both radiationinduced and spontaneous damages (Pollycove and Feinendegen 2003). Importantly, the reduction of the spontaneous rate of DNA damage that occur as a result of these processes can subsequently lead to reduced risk of cancer and various aging-associated conditions (Feinendegen et al. 2004). Moreover, other molecular mechanisms could also contribute to LDIR-triggered protective responses. The formation of specific DNA repair centers which arise as preferential sites of repair might be among such mechanisms. Such centers commonly referred to as radiation-induced foci, have been characterized by the local recruitment of p53 binding protein and other DNA damage sensing proteins (Neumaier et al. 2012).

\section{Endogenous antioxidant systems}

An increase of capability of endogenous antioxidant systems is another mechanism potentially contributing to hormetic effects (Sharma et al. 2019). It is commonly accepted that oxidative stress caused by excessive generation of ROS lead to damage of various cell components. Among detrimental effects induced by oxidative stress in biological systems, there are genetic instability and mutagenesis, mitochondrial dysfunction, membrane lysis, as well as cellular death (Di Meo et al. 2016; Islam 2017). Therefore, oxidative stress is regarded as an essential contributor in many chronic diseases including chronic inflammation, cardiovascular and neurodegenerative disorders, and also cancers. ROS excess may substantially contribute to aging process per see.g., through the accelerated telomere attrition (Koliada et al. 2015). Accumulating evidence from animal models indicate that exposure to LDIR may lead to activation of pathways involved in endogenous antioxidant defense, such as superoxide dismutase, catalase, glutathione, glutathione reductase and glutathione peroxidase in different tissues including spleen, liver, pancreas and brain, and it may cause stabilization of the ROS level (Kataoka et al. 2013; Sharma et al. 2019). These findings were confirmed in several human studies conducted in different occupational groups (Eken et al. 2012; Ahmad et al. 2016). The role of the transcription factor such as nuclear erythroid 2-related factor (Nrf2) involved in the transcriptional regulation of various genes contributed to antioxidant defense, including those encoding heme oxygenase-1, glutathione, superoxide dismutase and catalase, in driving hormesis-like adaptive responses has been also highlighted (Sekhar and Freeman 2015; Cameron et al. 2018). Nrf2 was shown to bind the antioxidant response element (ARE) and to activate some cytoprotective defense systems. For instance, acute irradiations with doses from 2 to 8 Gy have been shown to activate the ARE-dependent transcription in breast cancer cells (McDonald et al. 2010).

\section{Mitohormesis}

During last decades, important roles of ROS in multiple normal physiological processes have been revealed (Huang and Li 2020). They also play an essential role in various biosynthetic processes including the thyroid hormone production and cross-linking of extracellular matrix. Therefore, an excessively decreased ROS generation level may be likely associated with different pathological conditions. Impaired ROS cascade was found to be associated with hypothyroidism, low blood pressure, and also impaired antimicrobial defense (Milkovic et al. 2019). There is also increasing experimental evidence that caloric (dietary) restriction and several other experimental manipulations may extend lifespan via hormetic effects caused by increased production of ROS (mitohormesis) (Bárcena et al. 2018). Mitohormesis is a biological response where the induction of a mild mitochondrial stress by moderate ROS overproduction triggers certain signaling pathways, leading thereby to health benefits at a whole-organism level (Ristow 2014). The activation of the mitohormetic response was shown to be able to improve metabolism and immune system as well as to enhance longevity in various animal models, from worms to rodents (Bárcena et al. 2018). It is therefore suggested that LDIR can induce the body's defense mechanisms, including the enhanced antioxidant activity, in consequence of a slightly enhanced concentration of ROS. Therefore, LDIR is regarded by several authors as a reasonable alternative to treatments with exogenous antioxidant sources, which were repeatedly reported to be inefficient in clinical trials (Doss 2012). One plausible explanation for the failure of these clinical trials is that exogenous antioxidants might not be effectively delivered to target organs. LDIR, in 
contrast, may increase the capability of endogenous antioxidant systems in these organs. Therefore, LDIR may represent a promising therapy in treating pathological conditions caused by the oxidative damage of vital biomolecules (Doss 2012).

\section{Heat shock response}

The role of the heat shock response (coordinated induction of molecular chaperones such as heat shock proteins, HSPs) in producing hormetic effects has been elucidated (Lagisz et al. 2013; Dattilo 2015). Chaperone proteins are known to regulate both initial folding of proteins and subsequent maintenance of their structure. More specifically, this protein network is crucially involved in the de novo folding, refolding, and disaggregating damaged proteins. In a lot of cases, this network may refold damaged proteins to their normal functional state (Klaips et al. 2018). Integrated chaperone and protein-degradation networks are required to properly maintain a protein homeostasis (proteostasis). Furthermore, extracellular HSPs may stimulate an immune response. Therefore, their activation is considered as a promising treatment strategy to enhance anti-cancer immunity (Das et al. 2019; Yun et al. 2019). An important point in this regard is that capacity of the proteostasis network declines with age. The age- associated decline in the capacity of proteostasis may likely explain the increased prevalence of chronic disorders related to protein aggregation (e.g., neurodegenerative ones) in elderly (Gandhi et al. 2019; Webster et al. 2019). Production of HSPs represents a general response to any extreme stresses, including exposure to a high-dose radiation. Some studies indicated that expression of HSPs may be increased by LDIR exposure as well. For example, in the myeloid leukemia cell line, LDIR was shown to induce expression of the HSP70 mRNA (Ibuki et al. 1998). Irradiated cells also exhibited thermoresistance within one hour after irradiation and radioresistance within four hours after irradiation. Increased expression of Hsp25 and Hsp70 was found to be at least partly responsible for the induction of the adaptive response (a reduction of damaging effects caused by the high-level challenge dose through the low-dose priming exposure) in fibrosarcoma cells (Lee et al. 2002).
Apoptosis and autophagy

Low-dose/low-dose rate radiation has been consistently demonstrated to induce apoptosis (programmed cell death). Substantially enhanced rate of apoptosis was found, e.g., in HeLa and Hep2 cells following the low-dose/low-dose-rate radiation exposure (MirzaieJoniani and Eriksson 2002). It has been assumed by some authors that removal of damaged or senescent cells by apoptosis followed by compensatory cell proliferation may be a key mechanism in the radiationinduced adaptive responses (Kondo 1988). The radiation-induced generation of ROS may also cause of cellular "self-eating" involving degradation of various cellular components via lysosomal machinery, a process commonly referred to as autophagy (Szumiel 2012). Autophagy has been repeatedly found to be deregulated in most chronic pathological conditions, particularly age-related ones (Ren and Zhang 2018). Currently, autophagy induction is regarded as one of the most promising strategies in anti-aging medicine (Stead et al. 2019).

It should be certainly taken into account in discussing this subject that functional interactions of autophagy and apoptosis are quite complex. Indeed, autophagy enables adaptation to stress conditions known to suppress apoptosis; therefore, it represents an alternative pathway of cell death (Galluzzi et al. 2016). Autophagy and apoptosis, however, may be induced by the same stress conditions. Sometimes, these conditions result in combined autophagy and apoptosis; in other cases, cells switch between both these responses in a mutually exclusive way (Maiuri et al. 2007). Under the conditions of radiation-induced oxidative stress, the proper balance among normal metabolic functions of ROS and their damaging effects is likely a central factor in determining the cell's fate (Szumiel 2012). Radiation-induced adaptive (hormetic) responses are often accompanied by stimulated cellular proliferation. In particular, LDIR has been found to significantly enhance the proliferation rate of mesenchymal stem cells in vitro through activation of the mitogen-activated protein kinase/ extracellular-signal-regulated kinase (MAPK/ERK) signaling pathway known to play a pivotal role in cellular growth (Liang et al. 2011). Importantly, both early progenitor cells and hematopoietic stem cells were shown to be able to tolerate and adapt to being many times hit by the energy deposition events 
(Fliedner et al. 2012). Based on this, the authors proposed the "injured stem cell hypothesis" according to that it is assumed that radiation-injured stem cells may continue to deliver functionally active cells which may ensure the maintenance of hematopoietic homeostasis throughout entire life course. It can be therefore assumed that post-radiation compensatory proliferation of such cell clones might be one more potential mechanism for both the radiation-induced adaptive responses and hormetic effects.

\section{Immune response}

The central suggestion made, usually implicitly, by the LNT model is that radiation carcinogenesis is due to "one-track action", i.e., one or more DNA double strand breaks caused by a single electron track (Shah et al. 2012). The number of tracks is directly proportional to the dose. Cancer risk is therefore believed to be proportional to dose also, with any dose, no matter how small, able to induce cancer. This suggestion is, however, not consistent with multiple research findings indicating that mutation emergence is far from being the only causative event which triggers the development of clinical cancer. A considerable amount of evidence indicates that radiation may induce cancer not through simple stochastic events in a single cell but rather following complex systemic effects (Raabe 2011, 2014). Supportive evidence for this was provided from research performed in Japanese geriatric hospitals (Imaida et al. 1997). In this study, postmortem whole-body autopsies showed that percentage of patients carrying mutations indicative of cancer was about $40 \%$, and this mutation rate has been found to be relatively stable in the age range from 48 to 94 years. Importantly, the incidence of cancer-indicative mutations did not differ substantially among age groups, as if the cancer incidence was not age-dependent. This result was counter-intuitive because within this age range the cancer mortality rate is known to increase by about an order of magnitude both in Japan and in Western countries. This discrepancy may indicate that presence of neoplastic cells is not the only (and likely not the decisive) factor in the cancer initiation and progression. Another notable fact here is that immune suppression leads to more than doubled risk of cancer development in organ-transplant patients (Doss 2012). This is quite predictable, given the fact that immune system plays a determining role in tumor immunogenicity (Koebel et al. 2007). Furthermore, the immune system can suppress cancer growth by extending the period required for the neoplasm development, maintaining cancer in an equilibrium state and preventing undetected (occult) tumors from becoming clinical cancers. Therefore, it has been assumed that age-associated increase in cancer incidence could be a consequence of the agingrelated decline in immune function (Hong et al. 2019) rather than of occurrence of mutations per se (Doss 2012). It is therefore quite reasonable to expect that improvement of immune system may result in reducing cancer incidence. The responses of the immune system to irradiation have been demonstrated to be non-linear. High-dose radiation exposure is known to suppress the immune system, while LDIR may stimulate it. This is evident from multiple experimental studies (Hosoi and Sakamoto, 1993; Cui et al. 2017; Csaba 2019). The therapeutic potential of LDIR has been actively investigated for decades in various animal models of immune-associated pathological conditions, including autoimmune disorders and malignant tumors (for review, see Cui 2017).

The role of the adaptive immune response in carcinogenesis is also evident from studies where sporadic inhibition of distant untreated tumors following the irradiation of another part of the body was reported. Such inhibition is generally referred to as abscopal effect (a radiobiology term meaning "away from target") (Dagoglu et al. 2019; Wani et al. 2019; Welsh et al. 2020). The abscopal phenomenon is commonly assumed to have an immune origin and it indicates that local radiotherapy may cause wholebody systemic effects (Yilmaz et al. 2019). Since the immune system may be stimulated by LDIR, many authors suggest that abscopal effects most probably originate from adaptive immune response in body parts exposed to indirect LDIR in the process of the (high-dose) radiation therapy of distant parts of the body. In addition, there is some evidence that low dose total-body irradiation (without the standard localized high-dose radiotherapy) can lead to suppression of distant metastasis of cancerous cells (Welsh et al. 2020). Based on these considerations, it has been proposed to apply LDIR to induce abscopal effect with aim of inhibiting cancerous processes in those patients who were diagnosed with early-stage cancers during screening programs (Doss 2013). 


\section{Medical treatments that employ low doses of ionizing radiation}

Elucidating the biological mechanisms underlying radiation hormesis led to scientific perception of its reality and revitalization of research interest in this phenomenon. Over the past 15 years, several clinics in Japan began to provide hormesis therapy in small rooms that replicate the conditions of a typical natural radon spa. Some patients with severe medical conditions requested hormesis therapy after accepted treatments did not provide a remedy. When a significant improvement has been observed, a case report was written.

A recent article by Cuttler (2020) reviewed the application of low doses of ionizing radiation (LDIR) in medical therapies, from the discovery of X-rays and radioactivity in 1895/6 until the present. It discussed the political barrier against such therapies that was created in 1956 by the recommendation of the U.S. National Academy of Sciences to employ the LNT model to assess the risk of radiation-induced mutations (and cancer). The profound fundamental and clinical studies of Sakamoto et al. (1997) on cancer control, employing low doses of radiation, were pointed out and the excellent review by Pollycove (2007) on the radiobiological basis of LDIR treatments in the prevention and therapy of cancer was highlighted. The article outlined 13 recent cases of low-dose treatments in Japan with X-rays and radon to patients with different types of stage IV cancer (prostate, breast, colorectal, uterine, lung and liver cell) and to patients with severe autoimmune diseases (ulcerative colitis, pemphigus, type-1 diabetes, rheumatoid arthritis).

In the U.S., a patient in hospice with severe Alzheimer's disease (and her husband with Parkinson's disease) were treated successfully using CT scans of the brain (Cuttler et al. 2016, 2017a, b, 2018a, b). Subsequently, a pilot study was completed on five patients with severe Alzheimer's disease. It repeated the treatments described in the 2016 case report. The family members of four of the five patients observed significant improvements in cognition and behavior. (A manuscript on this clinical trial has been submitted to a medical journal.) In addition, four clinical trials are starting on low-dose radiotherapy of Alzheimer's disease using 5 or 10 dose fractions of $2 \mathrm{~Gy}$. Such exposures have been employed successfully to remove amyloid plaque in other areas of the body and produce anti-inflammatory effects in preclinical studies (Michael et al. 2019; Ceyzeriat et al. 2020; Kim et al. 2020a, 2020b). LDIR was also considered among the potential hormesisbased approaches in treating Parkinson's disease (Calabrese et al. 2018a). The anti-Parkinson's potential of such treatment modality was evident from findings from rodent models of Parkinson's disease (Kojima et al. 1999; El-Ghazaly et al. 2015).

Radiotherapy (RT) has been shown to have a potential as an effective and safe alternative to pharmacological therapies in treating different inflammatory conditions such as bursitis, tendonitis, arthritis, and also serious inflammatory lung conditions (for review, see Calabrese et al. 2018b). In these studies conducted mostly during the 1920 s to 1940 s, RT was reported to be efficient after only a single exposure, with ether short-term (within $24 \mathrm{~h}$ ) or long-term (lasting months to years) relief of symptoms. The polarization of macrophages to an anti-inflammatory or M2 phenotype was assumed as potential mechanism by which RT can mitigate inflammation and facilitate healing (Calabrese et al. 2018b). These findings are particularly promising in the context of the COVID-19 viral pandemic, which started in December 2019 and has had an enormous social and economic impact. Although the general population is commonly susceptible to the COVID-19, infected elderly patients demonstrate most fast progression and severe manifestations with a high proportion of the critical condition owing to the compromised immunity and underlying disorders (Wang et al. 2020). Extraordinary precautionary measures have been taken to control its high incidence of morbidity and mortality (Johns Hopkins University 2020), and intensive efforts have been underway to identify treatments and vaccines. Since the acute respiratory distress syndrome due to immune over-response is the deadliest symptom, the 1940s LDIR treatment such as $0.5 \mathrm{~Gy}$ X-ray of the lungs (Calabrese and Dhawan 2013) has emerged as a promising modality to treat COVID-19 (Algara et al. 2020; Cosset et al. 2020; Dhawan et al. 2020; Kirkby and Mackenzie 2020). Fourteen clinical trials are underway worldwide as for Oct 1, 2020 (U.S. National Library of Medicine 2020). Preliminary results (Del Castillo et al. 2020; Hess et al. 2020) are encouraging. 


\section{Conclusions}

LDIR has been successfully exploited for centuries (radon springs) to remediate arthritis and other diseases. In the first half of XX century, LDIR was successfully used for treating a range of diseases including pneumonia. However for the last half a century, application guidelines for ionizing radiation (as well as safety regulations) have been based on the LNT model assuming that health risk is proportional to the total radiation dose, no matter how low the dose and dose rate are. While LNT has never achieved a scientific consensus, the recent epidemiological evidence is less and less compatible with the assumption of linearity. More importantly, much information was accumulated on biological effects of LDIR, and the recent radiobiological evidence does not support the assumption of low-dose harm. Moreover, there is increasing evidence that LDIR, such as used in X-ray imaging including CT, is a hormetin-that is it affects health rather positively than negatively. Not accidentally, LNT is viewed as doubtful (and often-obsolete) by a growing part of the research community, though there are still many important topics that require further investigation. In this review, we aimed to summarize evidence supporting hormesis through LDIR. We also discussed here the possibility of clinical use of LDIR, predominantly for age-related disorders, e.g., Alzheimer's disease, for which no remedies are available (Socol et al. 2013). Indeed, due to the low average residual life expectancy in old patients, the short-term benefits of such interventions (e.g., potential therapeutic effect against dementia) may outweigh their hypothetical delayed risks (e.g., cancer).

When considering the effects of irradiation on human health, it is necessary to clearly distinguish between the effects of increased background radiation to which adaptation can occur over many generations at the population level and the effects of irradiation as a result of accidents or medical procedures. In addition, hormetic effects of acute and chronic radiation exposure and also of high- and low-linear energy transfer (LET) radiation conditions have to be separately considered.

Undoubtedly, caution should be exercised when introducing new medical practices, and LDIR therapy is no exception. However, bearing in mind the enormous social, economic and ethical implications of potentially-treatable, age-related disorders, we argue that assessment and clinical trials of LDIR treatments should be given priority.

Acknowledgements The authors thank Tatyana Papurina for the helpful technical assistance.

Author contributions AV and YS contributed to the study conception. All authors performed the literature search and data analysis. JMC critically revised the manuscript. All authors read and approved the final version of the manuscript.

\section{Compliance with ethical standards}

Conflict of interest The authors declare no conflict of interest.

\section{References}

Agathokleous E, Calabrese EJ (2020) A global environmental health perspective and optimisation of stress. Sci Total Environ 704:135263

Ahmad IM, Temme JB, Abdalla MY, Zimmerman MC (2016) Redox status in workers occupationally exposed to longterm low levels of ionizing radiation: a pilot study. Redox Rep 21(3):139-145

Algara M, Arenas M, Marin J, et al (2020) Low dose antiinflammatory radiotherapy for the treatment of pneumonia by covid-19: A proposal for a multi-centric prospective trial. Clin Transl Radiat Oncol 24:29-33

Allen RG (1985) Relationship between gamma-irradiation, life span, metabolic rate and accumulation of fluorescent age pigment in the adult male housefly, Musca domestica. Arch Gerontol Geriatr 4(2):169-178

Allen RG, Sohal RS (1982) Life-lengthening effects of gammaradiation on the adult housefly, Musca domestica. Mech Ageing Dev 20(4):369-375

Anzai K, Ban N, Ozawa T, Tokonami S (2012) Fukushima Daiichi nuclear power plant accident: facts, environmental contamination, possible biological effects, and countermeasures. J Clin BiochemNutr 50(1):2-8

Atkinson GF (1898) Report upon some preliminary experiments with Roentgen rays on plants. Science 7(158):7-13

Azzam EI, Colangelo NW, Domogauer JD et al (2016) Is ionizing radiation harmful at any exposure? An echo that continues to vibrate. Health Phys 110(3):249-251

Bárcena C, Mayoral P, Quirós PM (2018) Mitohormesis, an antiaging paradigm. Int Rev Cell Mol Biol 340:35-77

Blaufox MD (2019) Radioactive artifacts: historical sources of modern radium contamination. J Med Imaging Radiat Sci 50(4S1):S3-S17

Boothby TC (2019) Mechanisms and evolution of resistance to environmental extremes in animals. EvoDevo 10:30

Brown B (1966) Long-term radiation damage evaluation of lifespan studies.\&nbsp;Memorandum. RAND Corporation, Santa Monica. RM-5083-TAB 66

Brucer M (1990) A chronology of nuclear medicine. Heritage Publications, St. Louis 
Calabrese EJ (2014) Low doses of radiation can enhance insect lifespans. Biogerontology 14(4):365-381

Calabrese EJ (2018) Hormesis: path and progression to significance. Int J Mol Sci 19(10):2871

Calabrese EJ (2019) The dose-response revolution: how hormesis became significant: an historical and personal reflection. In: Rattan SIS, Kyriazis M (eds) The science of hormesis in health and longevity. Academic Press, London, pp 3-24

Calabrese EJ (2020) The Muller-Neel dispute and the fate of cancer risk assessment. Environ Res 190:109961

Calabrese EJ, Baldwin LA (2000) The effects of gamma rays on longevity. Biogerontology 1:309-319

Calabrese EJ, Dhawan G (2013) How radiotherapy was historically used to treat pneumonia: could it be useful today? Yale J Biol Med 86(4):555-570

Calabrese V, Cornelius C, Dinkova-Kostova AT, Calabrese EJ, Mattson MP (2010) Cellular stress responses, the hormesis paradigm, and vitagenes: novel targets for therapeutic intervention in neurodegenerative disorders. Antioxid Redox Signal 13(11):1763-1811

Calabrese EJ, Dhawan G, Kapoor R, Iavicoli I, Calabrese V (2015) What is hormesis and its relevance to healthy aging and longevity? Biogerontology 16(6):693-707

Calabrese EJ, Dhawan G, Kapoor R, Kozumbo WJ (2019) Radiotherapy treatment of human inflammatory diseases and conditions: optimal dose. Hum Exp Toxicol 38(8):888-898

Calabrese EJ, Tsatsakis A, Agathokleous E, Giordano J, Calabrese V (2020) Does green tea induce hormesis? Dose response 18(3): 1559325820936170

Cameron JR (2003) Longevity is the most appropriate measure of health effects of radiation. Radiology 229(1):14-15

Cameron BD, Sekhar KR, Ofori M, Freeman ML (2018) The rle of Nrf2 in the response to normal tissue radiation injury. Radiat Res 190(2):99-106

Caratero A, Courtade M, Bonnet L, Planel H, Caratero C (1998) Effect of a continuous gamma irradiation at a very low dose on the life span of mice. Gerontology 44(5):272-276

Carlson LD, Jackson BH (1959) The combined effects of ionizing radiation and high temperature on the longevity of the Sprague-Dawley rat. Radiat Res 11:509-519

Carlson LD, Scheyer WJ, Jackson BH (1957) The combined effects of ionizing radiation and low temperature on the metabolism, longevity and soft tissue of the white rat. Radiat Res 7(2):190-195

Ceyzeriat K, Tournier BB, Miller P, Frisoni GB, Garibotto V, Zilli T (2020) Low-dose radiation therapy: a new treatment strategy for Alzheimer's disease? J Alzheimer's Dis 74(2):411-419

Conter A, Dupouy D, Planel H (1983) Demonstration of a biological effect of natural ionizing radiation. Int $\mathrm{J}$ Rad Biol 43(4):421-432

Cork JM (1957) Gamma-radiation and longevity of the flour beetle. Radiat Res 7(6):551-557

Cosset JM, Deutsch É, Bazire L, Mazeron JJ, Chargari C (2020) Irradiation pulmonaire à faible dose pour l'orage de cytokines du COVID-19: pourquoi pas? [Low dose lung radiotherapy for COVID-19-related cytokine storm syndrome: Why not?]. Cancer Radiother 24(3):179-181.
Costantini D, Borremans B (2019) The linear no-threshold model is less realistic than threshold or hormesis-based models: an evolutionary perspective. Chem Biol Interact 301(1):26-33

Courtade M, Billote C, Gasset G et al (2002) Life span, cancer and non-cancer diseases in mouse exposed to a continuous very low dose of gamma irradiation. Int J Radiat Biol 78(9):845-855

Csaba G (2019) Hormesis and immunity: a review. Acta Microbiol Immunol Hung 66(2):155-168

Cui J, Yang G, Pan Z (2017) Hormetic response to low-dose radiation: focus on the immune system and its clinical implications. Int J Mol Sci 18(2):280

Cuttler JM (2020) Application of low doses of ionizing radiation in medical therapies. Dose Response 18(1):1-17

Cuttler JM, Moore ER, Hosfeld VD, Nadolski DL (2016) Treatment of Alzheimer disease with CT scans: a case report. Dose Response 14(2):1-7

Cuttler JM, Feinendegen LE, Socol Y (2017a) Evidence that lifelong low dose rates of ionizing radiation increase lifespan in long- and short-lived dogs. Dose Response 15(1): 1559325817692903

Cuttler JM, Moore ER, Hosfeld VD, Nadolski DL (2017b) Update on a patient with Alzheimer disease treated with CT scans. Dose Response 15(1):1-2

Cuttler JM, Feinedegen LE, Socol Y (2018a) Evidence of a dose-rate threshold for life span reduction of dogs exposed lifelong to $\gamma$-radiation. Dose Response 16(4): 1559325818820211

Cuttler JM, Moore ER, Hosfeld VD, Nadolski DL (2018b) 2nd update on a patient with Alzheimer disease treated with CT scans. Dose Response 16(1):1-2

Cypser JR, Johnson TE (2002) Multiple stressors in Caenorhabditis elegans induce stress hormesis and extended longevity. J Gerontol Biol Sci 57(3):109-114

Dagoglu N, Karaman S, Caglar HB, Oral EN (2019) Abscopal effect of radiotherapy in the immunotherapy era: systematic review of reported cases. Cureus 11(2):e4103

Das JK, Xiong X, Ren X, Yang JM, Song J (2019) Heat shock proteins in cancer immunotherapy. J Oncol 2019:3267207

Dattilo S, Mancuso C, Koverech G et al (2015) Heat shock proteins and hormesis in the diagnosis and treatment of neurodegenerative diseases. Immun Ageing 12(1):20

Davey WP (1917) The effect of X-rays on the length of life of Tribolium confusum. J Exp Zool 22(3):573-592

Davey WP (1919) Prolongation of life of Tribolium confusum apparently due to small doses of X-rays. J Exp Zool 28(3):447-458

Dhawan G, Kapoor R, Dhawan R, Singh R, Monga B, Giordano J, Calabrese EJ (2020) Low dose radiation therapy as a potential life saving treatment for COVID-19-induced acute respiratory distress syndrome (ARDS). Radiother Oncol 147:212-216

Di Meo S, Reed TT, Venditti P, Victor VM (2016) Role of ROS and RNS sources in physiological and pathological conditions. Oxid Med Cell Longev 2016:1245049

Dobrzyński L, Fornalski KW, Reszczyńska J, Janiak MK (2019) Modeling cell reactions to ionizing radiation: from a lesion to a cancer. Dose Response 17(2): 1559325819838434

Doss M (2012) Shifting the paradigm in radiation safety. Dose Response 10(4):562-583 
Doss M (2013) The importance of adaptive response in cancer prevention and therapy. Med Phys 40(3):030401

Ducoff HS (1975) Form of the increased longevity of Tribolium after X-irradiation. Exp Gerontol 10(3-4):189-193

Ducoff HS, Lee YJ (1984) Radiation-induced resistance to heat and to oxygen. In: Overgaard J (ed) Hyperthermic Oncology. Taylor \& Francis, London, pp 297-300

Ebrahimian TG, Beugnies L, Surette J (2018) Chronic exposure to external low-dose gamma radiation induces an increase in anti-inflammatory and anti-oxidative parameters resulting in atherosclerotic plaque size reduction in ApoE-/- mice. Radiat Res 189(2):187-196

Eken A, Aydin A, Erdem O et al (2012) Induced antioxidant activity in hospital staff occupationally exposed to ionizing radiation. Int J Radiat Biol 88(9):648-653

El-Ghazaly MA, Sadik NA, Rashed ER, Abd-El-Fattah AA (2015) Neuroprotective effect of EGb761® and low-dose whole-body $\gamma$-irradiation in a rat model of Parkinson's disease. Toxicol Ind Health 31(12):1128-1143.

Feinendegen LE, Pollycove M, Sondhaus CA (2004) Responses to low doses of ionizing radiation in biological systems. Nonlinearity Biol Toxicol Med 2(3):143-171.

Feinendegen LE (2005) Evidence for beneficial low level radiation effects and radiation hormesis. $\mathrm{Br} \mathrm{J}$ Radiol 78(925):3-7

Feinendegen LE, Pollycove M, Neumann RD (2007) Wholebody responses to low-level radiation exposure: new concepts in mammalian radiobiology. Exp Hematol 35(4S1):37-46

Fliedner TM, Graessle DH, Meineke V, Feinendegen LE (2012) Hemopoietic response to low dose-rates of ionizing radiation shows stem cell tolerance and adaptation. Dose Response 10(4):644-663

Galluzzi L, Bravo-San Pedro JM, Kepp O, Kroemer G (2016) Regulated cell death and adaptive stress responses. Cell Mol Life Sci 73(11-12):2405-2410

Gandhi J, Antonelli AC, Afridi A (2019) Protein misfolding and aggregation in neurodegenerative diseases: a review of pathogeneses, novel detection strategies, and potential therapeutics. Rev Neurosci 30(4):339-358

Giess MC (1980) Differences between natural ageing and radioinduced shortening of the life expectancy in Drosophila melanogaster. Gerontology 26(6):301-310

Giess MC, Planel H (1973) Effect of radioprotection at different periods on the longevity of Drosophila melanogaster. C R Acad Sci Hebd Seances Acad Sci D 276(6):1029-1032

Giess MC, Planel H (1977) Influence of sex on the radiationinduced lifespan modifications in Drosophila melanogaster. Gerontology 23(5):325-333

Giess MC, Cazeaux S, Murat M (1980) Post-radiative sterility and lifespan in males and females of Drosophila melanogaster. Exp Gerontol 15(6):503-510

Gould AB, Clark AM (1977) X-ray induced mutations causing adult life-shorting in Drosophila melanogaster. Exp Gerontol 12(3-4):107-112

Hess CB, Buchwald ZS, Stokes W et al (2020) Low-dose whole-lung radiation for COVID-19 pneumonia. Int $\mathrm{J}$ Radiation Oncol Biol Phys. https://doi.org/10.1016/j. ijrobp.2020.07.026

Hong H, Wang Q, Li J, Liu H, Meng X, Zhang H (2019) Aging, cancer and immunity. J Cancer 10(13):3021-3027
Hosoi Y, Sakamoto K (1993) Suppressive effect of low dose total body irradiation on lung metastasis: dose dependency and effective period. Radiother Oncol 26(2):177-179

Howell RW (2016) Physical considerations for understanding responses of biological systems to low doses of ionizing radiation: nucleosome clutches constitute a heterogeneous distribution of target volumes. Health Phys 110(3):283-286

Huang MZ, Li JY (2020) Physiological regulation of reactive oxygen species in organisms based on their physicochemical properties. Acta Physiol (Oxf) 228(1):e13351

Ibuki Y, Hayashi A, Suzuki A, Goto R (1998) Low-dose irradiation induces expression of heat shock protein $70 \mathrm{mRNA}$ and thermo- and radio-resistance in myeloid leukemia cell line. Biol Pharm Bull 21(5):434-439

Imaida K, Hasegawa R, Kato T et al (1997) Clinicopathological analysis on cancers of autopsy cases in a geriatric hospital. Pathol Int 47(5):293-300

Ina Y, Sakai K (2004) Prolongation of life span associated with immunological modification by chronic low-dose-rate irradiation in MRL-lpr/lpr mice. Radiat Res 161(2):168-173

Ina Y, Sakai K (2005) Furtherstudy of prolongation of life span associated with immunological modification by chronic low-dose-rate irradiation in MRL-lpr/lpr mice: effects of whole life irradiation. Radiat Res 163(4):418-423

Islam MT (2017) Radiation interactions with biological systems. Int J Radiat Biol 93(5):487-493

Jaworowski Z (1997) Radiation 3.5 billion years ago. 21st Century Sci Technol 10:4

Johns Hopkins University (2020) COVID-19 Dashboard by the CSSE. https://coronavirus.jhu.edu/map.html

Johnson TE, Hartman PS (1988) Radiation effects on life span in Caenorhabditis elegans. J Gerontol 43(5):137-141

Kataoka T (2013) Study of antioxidative effects and anti-inflammatory effects in mice due to low-dose $\mathrm{X}$-irradiation or radon inhalation. J Radiat Res 54(4):587-596

Kim BM, Hong Y, Lee S (2015) Therapeutic implications for overcoming radiation resistance in cancer therapy. Int $\mathbf{J}$ Mol Sci 16(11):26880-26913

Kim S, Nam Y, Kim C (2020) Neuroprotective and anti-inflammatory effects of low-moderate dose ionizing radiation in models of Alzheimer's disease. Int $\mathrm{J}$ Mol Sci 21(10):3678

Kim S, Chung H, Mai HN (2020) Low-dose ionizing radiation modulates microglia phenotypes in the models of Alzheimer's disease. Int J Mol Sci 21(12):4532

Kirkby C, Mackenzie M (2020) Low dose lung radiation therapy for pneumonia: an examination of historical dose distributions. Phys Med Biol 65(15):155019

Klaips CL, Jayaraj GG, Hartl FU (2018) Pathways of cellular proteostasis in aging and disease. J Cell Biol 217(1):51-63

Kodaira M, Izumi S, Takahashi N, Nakamura N (2004) No evidence of radiation effect on mutation rates at hypervariable minisatellite loci in the germ cells of atomic bomb survivors. Radiat Res 162(4):350-356

Koebel CM, Vermi W, Swann JB et al (2007) Adaptive immunity maintains occult cancer in an equilibrium state. Nature 450:903-907

Kojima S, Matsuki O, Nomura T, Yamaoka K, Takahashi M, Niki E (1999) Elevation of antioxidant potency in the brain 
of mice by low-dose gamma-ray irradiation and its effect on 1-methyl-4-phenyl-1,2,3,6-tetrahydropyridine (MPTP)induced brain damage. Free Radic Biol Med 26(34):388-395.

Koliada AK, Krasnenkov DS, Vaiserman AM (2015) Telomeric aging: mitotic clock or stress indicator? Front Genet 6:82

Kondo S (1988) Altruistic cell suicide in relation to radiation hormesis. Int J Radiat Biol Relat Stud Phys Chem Med 53(1):95-102

Koval L, Proshkina E, Shaposhnikov M, Moskalev A (2020) The role of DNA repair genes in radiation-induced adaptive response in Drosophila melanogaster is differential and conditional. Biogerontology 21(1):45-56

Lagisz M, Hector KL, Nakagawa S (2013) Life extension after heat shock exposure: assessing meta-analytic evidence for hormesis. Ageing Res Rev 12(2):653-660

Lamb MJ (1964) The effect of radiation on the longevity of female Drosophila subobscura. J Insect Physiol 10(3):487-497

Lee YJ, Ducoff HS (1983) Age and sensitivity to oxygen in the flour beetle, Tribolium confusum. Mech Age Dev 22(2):97-103

Lee YJ, Ducoff HS (1984) Radiation-enhanced resistance to oxygen: a possible relationship to radiation-enhanced longevity. Mech Age Dev 27(1):101-109

Lee YJ, Park GH, Cho HN et al (2002) Induction of adaptive response by low-dose radiation in RIF cells transfected with Hspb1 (Hsp25) or inducible Hspa (Hsp70). Radiat Res 157(4):371-377

Liang X, So YH, Cui J et al (2011) The low-dose ionizing radiation stimulates cell proliferation via activation of the MAPK/ERK pathway in rat cultured mesenchymal stem cells. J Radiat Res 52(3):380-386

Lorenz E, Jacobson LO, Heston EW (1954) Effects of longcontinued total-body gamma irradiation on mice, guinea pigs, and rabbits. III. Effects on life span, weight, blood picture, and carcinogenesis and the role of the intensity of radiation. In: Zirkle RE (ed) Biological effects of $\mathrm{X}$ and gamma radiation. McGraw-Hill, New York, pp 24-148

Lorenz E, Hollcroft JW, Miller E, Congdon CC, Schweisthal R (1955) Long-term effects of acute and chronic irradiation in mice. I. Survival and tumor incidence following chronic irradiation of $0.11 \mathrm{r}$ per day. J Natl Cancer Inst 15(4):1049-1058

Maiuri MC, Zalckvar E, Kimchi A, Kroemer G (2007) Selfeating and self-killing: crosstalk between autophagy and apoptosis. Nat Rev Mol Cell Biol 8(9):741-752

McDonald JT, Kim K, Norris AJ et al (2010) Ionizing radiation activates the Nrf2 antioxidant response. Cancer Res 70(21):8886-8895

Michael DB, Wilson GD, Hanna A (2019) Radiation therapy for the treatment of Alzheimer's disease. Neurol Neurosurg 2:1-6

Milkovic L, Cipak Gasparovic A, Cindric M, Mouthuy PA, Zarkovic N (2019) Short overview of ROS as cell function regulators and their implications in therapy concepts. Cells 8(8):793

Mirzaie-Joniani H, Eriksson D, Sheikholvaezin A et al (2002) Apoptosis induced by low-dose and low-dose-rate radiation. Cancer 94(4 Suppl):1210-1214
Mohsin A (1979) The sparing effect of dose-fractionation in adult Drosophila. Experientia 35(6):746-747

Moskalev AA, Zainullin VG (2001) Role of apoptotic cell death in radio induced aging in Drosophila melanogaster. Radiats Biol Radioecol 41(6):650-652

Moskalev AA, Zainullin VG (2004) Aging rate after continual low dose irradiation of Drosophila strains with apoptosis deregulation. Radiats Biol Radioecol 44(2):156-161

Moskalev AA, Iatskiv AS, Zainullin VG (2006) Effect of lowdose irradiation on the lifespan in various strains of Drosophila melanogaster. Genetika 42:773-782

Moskalev A, Shaposhnikov M, Turysheva E (2009) Life span alteration after irradiation in Drosophila melanogaster strains with mutations of Hsf and Hsps. Biogerontology 10(1):3-11

Moskalev AA, Plyusnina EN, Shaposhnikov MV (2011) Radiation hormesis and radioadaptive response in Drosophila melanogaster flies with different genetic backgrounds: the role of cellular stress-resistance mechanisms. Biogerontology 12(3):253-263

Mothersill C, Rusin A, Seymour C (2019) Relevance of nontargeted effects for radiotherapy and diagnostic radiology; a historical and conceptual analysis of key players. Cancers (Basel) 11(9):1236

Musci RV, Hamilton KL, Linden MA (2019) Exercise-induced mitohormesis for the maintenance of skeletal muscle and healthspan extension. Sports (Basel) 7(7):170

Nelson FR (1973) Drosophila melanogaster: effects of gamma radiation on fecundity and longevity. $\mathrm{J}$ Econ Entomol 66(1):257-258

Nenoi M, Wang B, Vares G (2015) In vivo radioadaptive response: a review of studies relevant to radiation-induced cancer risk. Hum Exp Toxicol 34(3):272-283

Neumaier T, Swenson J, Pham C et al (2012) Evidence for formation of DNA repair centers and dose-response nonlinearity in human cells. Proc Natl Acad Sci USA 109(2):443-448

Paithankar JG, Deeksha K, Patil RK (2017) Gamma radiation tolerance in different life stages of the fruit fly Drosophila melanogaster. Int J Radiat Biol 93(4):440-448

Planel H, Giess MC (1973) Decrease in the longevity of Drosophila melanogaster caused by protection against natural ionizing radiations. C R Acad Sci Hebd Seances Acad Sci D 676(5):809-812

Planel H, Soleilhavoup JP, Blanc D, Fontan J, Tixador R (1966) Action of the gamma radiation of thorium on the growth of Paramecium caudatum and Paramecium aurelia grown under adioprotective apparatus. C R Acad Sci Hebd Seances Acad Sci D 160(5):1090-1093

Planel H, Soleilhavoup JP, Giess MC, Tixador R (1967a) Demonstration of a retardation of development of Drosophila melanogaster by diminution of environmental natural radioactivity. C R Acad Sci Hebd Seances Acad Sci D 264(6):865-868

Planel H, Soleilhavoup JP, Giess MC, Tixador R (1967b) Action of natural ionizing radiations on the reproduction of metazoa: studies on Drosophila. C R Acad Sci Hebd Seances Acad Sci D 264(5):755-758

Planel H, Soleilhavoup JP, Cottin F, Tixador R, Richoilley G (1969) Biologic action of natural irradiation: study of the growth of Paramecium aurelia and Paramecium caudatum 
in a subterranean laboratory. C R Acad Sci Hebd Seances Acad Sci D 269(17):1697-1700

Planel H, Soleilhavoup JP, Tixador R et al (1987) Influence on cell proliferation of background radiation or exposure to very low, chronic gamma radiation. Health Phys 52(5):571-578

Pollycove M (2007) Radiobiological basis of low-dose irradiation in prevention and therapy of cancer. Dose Response 5(1):1-13

Pollycove M, Feinendegen LE (2003) Radiation-induced versus endogenous DNA damage: possible effect of inducible protective responses in mitigating endogenous damage. Hum Exp Toxicol 22(6):290-306

Pouget JP, Georgakilas AG, Ravanat JL (2018) Targeted and off-target (Bystander and Abscopal) effects of radiation therapy: redox mechanisms and risk/benefit analysis. Antioxid Redox Signal 29(15):1447-1487

Raabe OG (2010) Concerning the health effects of internally deposited radionuclides. Health Phys 98(3):515-536

Raabe OG (2011) Toward improved ionizing radiation safety standards. Health Phys 101(1):84-93

Raabe OG (2014) Concerning radiation carcinogenesis. Health Phys 107(6):571

Raabe OG (2015) Concerning ionizing radiation-induced cancer from internally deposited radionuclides. Int J Radiat Biol 91(10):810-819

Rattan SIS, Kyriazis M (eds) (2019) The science of hormesis in health and longevity. Academic Press, London

Ren J, Zhang Y (2018) Targeting autophagy in aging and agingrelated cardiovascular diseases. Trends Pharmacol Sci 39(12):1064-1076

Ristow M (2014) Unraveling the truth about antioxidants: mitohormesis explains ROS-induced health benefits. Nat Med 20(7):709-711

Rogina B (2011) For the special issue: aging studies in Drosophila melanogaster. Exp Gerontol 46(5):317-319

Rothkamm K, Lobrich M (2003) Evidence for a lack of DNA double-strand break repair in human cells exposed to very low X-ray doses. Proc Natl Acad Sci USA 100(9):5057-5062

Sacher GA (1956) On the statistical nature of mortality, with especial reference to chronic radiation mortality. Radiology $67(2): 250-257$

Sacher GA (1963) Effects of X-rays on the survival of Drosophila imagoes. PhysiolZool 36(4):295-311

Sacher GA (1977) Life table modification and life prolongation. In: Finch CE, Hayflick L (eds) Handbook of the biology of aging. Van Nostrand Reinhold Co, New York, pp 582-638

Sakamoto K, Myojin M, Hosoi Y et al (1997) Fundamental and clinical studies on cancer control with total or half body irradiation. J Jpn Soc Ther Radiol 9(3):161-175

Satoh C, Takahashi N, Asakawa J et al (1996) Genetic analysis of children of atomic bomb survivors. Environ Health Perspect 104(Suppl 3):511-519

Schulz H (1887) Zur Lehre von der Arzneiwirdung. Virchows Arch Pathol Anat Physiol Fur Klin Med 108:423-445

Schulz H (1888) Uber Hefegifte. Pflugers Arch Gesamte Physiol Mensch Tiere 42:517-541

Scott BR (2014) Radiation-hormesis phenotypes, the related mechanisms and implications for disease prevention and therapy. J Cell Commun Signal 8(4):341-352
Scott BR, Tharmalingam S (2019) The LNT model for cancer induction is not supported by radiobiological data. Chem Biol Interact 301:34-53

Sekhar KR, Freeman ML (2015) Nrf2 promotes survival following exposure to ionizing radiation. Free Radic Biol Med 88(Pt B):268-274

Seong KM, Kim CS, Seo SW et al (2011) Genome-wide analysis of low-dose irradiated male Drosophila melanogaster with extended longevity. Biogerontology 12(2):93-107

Shah DJ, Sachs RK, Wilson DJ (2012) Radiation-induced cancer: a modern view. Br J Radiol 85(1020):e1166-e1173

Shameer PM, Sowmithra K, Harini BP, Chaubey RC, Jha SK, Shetty NJ (2015) Does exposure of male Drosophila melanogaster to acute gamma radiation influence egg to adult development time and longevity of F1-F3 offspring? Entomol Sci 18:368-376

Sharma S, Singla N, Chadha VD, Dhawan DK (2019) A concept of radiation hormesis: stimulation of antioxidant machinery in rats by low dose ionizing radiation. Hell J Nucl Med 22(1):43-48

Shibamoto Y, Nakamura H (2018) Overview of biological, epidemiological, and clinical evidence of radiation hormesis. Int J Mol Sci 19(8):2387

Socol Y, Dobrzyński L, Doss M et al (2013) Commentary: ethical issues of current health-protection policies on lowdose ionizing radiation. Dose Response 12(2):342-348

Southam CM, Erhlich J (1943) Effects of extracts of western red-cedar heartwood on certain wood-decaying fungi in culture. Phytopathology 33:517-524

Stead ER, Castillo-Quan JI, Miguel VEM et al (2019) Agephagy — adapting autophagy for health during aging. Front Cell Dev Biol 7:308

Suzuki K, Yamashita S (2012) Low-dose radiation exposure and carcinogenesis. Jpn J Clin Oncol 42(7):563-568

Szumiel I (2012) Radiation hormesis: Autophagy and other cellular mechanisms. Int J Radiat Biol 88(9):619-628

Tanaka S, Tanaka IB III, Sasagawa S et al (2003) No lengthening of life span in mice continuously exposed to gamma rays at very low dose rates. Radiat Res 160(3):376-379

Thompson GA, Smithers J, Boxenbaum H (1990) Biphasic mortality response of chipmunks in the wild to single doses of ionizing radiation: toxicity and longevity hormesis. Drug MetabRev 22(2-3):269-289

UNSCEAR (1958) Report of the United Nations Scientific Committee on the Effects of Atomic Radiation. General Assembly Official Records: Thirteenth Session Suppl 17(A/3838). United Nations, New York

U.S. National Library of Medicine (2020) Registry of Clinical Trials: COVID-19, low dose radiation. U.S. National Library of Medicine, Bethesda

Vaiserman AM (2008) Epigenetic engineering and its possible role in anti-aging intervention. Rejuvenation Res 11(1):39-42

Vaiserman AM (2010) Hormesis, adaptive epigenetic reorganization, and implications for human health and longevity. Dose Response 8(1):16-21

Vaiserman AM, Koshel NM, Litoshenko AY, Mozzhukhina TG, Voitenko VP (2003a) Effects of X-irradiation in early ontogenesis on the longevity and amount of the S1 nuclease-sensitive DNA sites in adult Drosophila melanogaster. Biogerontology 4(1):9-14 
Vaiserman AM, Litoshenko AY, Kvitnitskaia-Ryzhova TI (2003b) Molecular and cellular aspects of radiation hormesis in Drosophila melanogaster. Tsitol Genet 37(3):41-48

Vaiserman AM, Koshel NM, Voitenko VP (2004a) Effect of $\mathrm{X}$-irradiation at larval stage on adult lifespan in Drosophila melanogaster. Biogerontology 5(1):49-54

Vaiserman AM, Koshel NM, Mechova LV, Voitenko VP (2004b) Cross-life stage and crossgenerational effects of gamma irradiations at the egg stage on Drosophila melanogaster life histories. Biogerontology 5(5):327-337

Vaiserman A, Koliada A, Zabuga O, Socol Y (2018) Health impacts of low-dose ionizing radiation: current scientific debates and regulatory issues. Dose Response 16(3):1559325818796331

Wani SQ, Dar IA, Khan T, Lone MM, Afroz F (2019) Radiation therapy and its effects beyond the primary target: an abscopal effect. Cureus 11(2):e4100

Wang Y, Zhang L, Sang L, et al. (2020) Kinetics of viral load and antibody response in relation to COVID-19 severity. J Clin Invest 130(10):5235-5244

Webster JM, Darling AL, Uversky VN, Blair LJ (2019) Small heat shock proteins, big impact on protein aggregation in neurodegenerative disease. Front Pharmacol 10:1047

Welsh J, Bevelacqua JJ, Dobrzyński L, Mortazavi SAR, FarjadianSh, Mortazavi SMJ (2020) Abscopal effect following radiation therapy in cancer patients: a new look from the immunological point of view. J Biomed Phys Eng 10(4):537-542

Yamauchi K, Ono T, Ayabe Y et al (2019) Life-shortening effect of chronic low-dose-rate irradiation in calorie-restricted mice. Radiat Res 192(4):451-455

Yeargers E (1981) Effect of gamma-radiation on dauer larvae of Caenorhabditis elegans. J Nematol 13(2):235-237

Yilmaz MT, Elmali A, Yazici G (2019) Abscopal effect, from myth to reality: from radiation oncologists' perspective. Cureus 11(1):e3860

Yun CW, Kim HJ, Lim JH, Lee SH (2019) Heat shock proteins: agents of cancer development and therapeutic targets in anti-cancer therapy. Cells 9(1):60

Zainullin VG, Moskalev AA (2001) Radiation-induced changes in the life span of laboratory Drosophila melanogaster strains. Russ J Genet 37(9):1094-1095

Zhikrevetskaya S, Peregudova D, Danilov A et al (2015) Effect of low doses (5-40 cGy) of gamma-irradiation on lifespan and stress-related genes expression profile in Drosophila melanogaster. PLoS One 10(8):e0133840

Publisher's Note Springer Nature remains neutral with regard to jurisdictional claims in published maps and institutional affiliations. 